\title{
HER E ANDROIDES SONHAM COM OVELHAS ELÉTRICAS?: Uma análise da relação entre tecnologia e design
}

\author{
Júlio César Machado Pinto ${ }^{1}$ \\ Marcela Nascimento Gontijo ${ }^{2}$
}

Resumo: As antecipações para o futuro da cidade de Los Angeles são bastante antitéticas se considerarmos as previsões feitas por Hollywood. Se por um lado o filme $\mathrm{Her}$ (2013), de Spike Jonze, apresenta uma atmosfera mais promissora e amigável, por outro lado, tanto o filme Blade Runner (1982), quanto o livro de Philip K. Dick, Androides sonham com ovelhas elétricas?, no qual Ridley Scott se baseou para fazer seu filme, retrata uma cidade mais apocalíptica e caótica. Este artigo propõe-se a fazer, portanto, uma análise destas duas Los Angeles tão distintas, entre o futuro estetizado de Her e o caótico de Androides sonham com ovelhas elétricas?, fazendo assim uma breve comparação das semelhanças e diferenças e refletindo sobre a função da tecnologia e do design nas obras.

Palavras-chave: Her. Androides Sonham com Ovelhas Elétricas. Blade Runner. Design. Tecnologia.

Abstract: The anticipations regarding the future of Los Angeles are quite antithetical if we consider the predictions made by Hollywood. On the one hand, the movie Her (2013), directed by Spike Jonze, presents a more promising and friendly atmosphere. On the other hand, both the movie Blade Runner (1982) and the book by Philip K. Dick, Do androids dream of electric sheep?, used by Ridley Scott to base his movie on, portray a more apocalyptic and chaotic town. This essay proposes to, therefore, make an analysis of this two different Los Angeles, between the aestheticized of Her and the chaotic one of Do Androids Dream of Electric Sheep?, making so a brief comparison of similarities and differences and reflecting upon the function of both technology and design in the works.

Keywords: Her. Do Androids Dream of Electric Sheep. Blade Runner. Design. Technology.

\section{Her e Androides sonham com ovelhas elétricas?: Uma análise da relação entre tecnologia e design}

No que tange o futuro, o que está por vir é quase sempre uma grande incógnita. As antecipações para o futuro da cidade de Los Angeles, por exemplo, são bastante antitéticas se considerarmos as previsões feitas por Hollywood. Por um lado o filme Her (2013), com direção de Spike Jonze, apresenta uma atmosfera mais promissora e amigável para a cidade americana. Por outro lado, tanto o filme Blade Runner (1982), quanto o livro de Philip K.

\footnotetext{
1 Júlio Pinto é Ph.D. pela University of North Carolina at Chapel Hill, EUA e realizou estudos de pósdoutoramento na Universidade Católica Portuguesa, em Lisboa.

2 Marcela Gontijo é graduada em Publicidade e Propaganda pela PUC Minas e atualmente é graduanda em Letras pela UFMG. E-mail: marcela.n.gontijo@gmail.com.
} 
Dick, Androides sonham com ovelhas elétricas?, no qual Ridley Scott se baseou para fazer seu filme, retratam uma Los Angeles mais apocalíptica e caótica.

Este artigo propõe-se a fazer, portanto, uma análise destas duas Los Angeles tão diferentes. Entre o futuro estetizado de Her e o caótico de Androides sonham com ovelhas elétricas? e Blade Runner buscaremos fazer uma breve comparação das aproximações e distanciamentos, bem como refletir sobre a estética e a função da tecnologia e do design em ambos os cenários. Para tal, usaremos como embasamento teórico textos de autores como Gilles Lipovetsky e Giselle Beiguelman que analisam, respectivamente, a sociedade de consumo pós-moderna e o chamado "capitalismo fofinho", além de uma análise geral da linguagem do design feita por Deyan Sudjic, diretor do Design Museum de Londres.

\section{Her}

O filme de Spike Jonze mostra uma cidade futurista, organizada, próspera, limpa e automatizada (BONTEMPO, 2014). Os arranha-céus cinzas e pouco expressivos desenham o horizonte da cidade e ajudam a construir a sensação de um lugar impessoal e genérico. Filmado em Los Angeles e Xangai, o filme usa a arquitetura das duas cidades para construir seu próprio mundo (INTERIORS, 2014), sem, no entanto, dar tanto enfoque à perspectiva arquitetônica na construção da narrativa, mas, ainda assim, utilizando-a como agente na trama. Jonze, o produtor e diretor, em conjunto com o designer de produção K. K. Barrett, buscaram utilizar a ambiência urbana para refletir, sobretudo, as questões emocionais dos personagens ao longo do filme.

Os figurinos, a decoração, as estampas e as cores, por outro lado, usam um matiz de tons mais quentes, como vermelho, rosa, laranja e amarelo, criando um ar vintage num cenário futurista, resgatando diversas tendências estéticas do século 20: as roupas têm referências das décadas de 20 e 40 e o mobiliário das décadas de 50, 60 e 80. E, até mesmo alguns dos dispositivos tecnológicos que aparecem tiveram o design inspirado em acessórios da década de 1940 (Barrett citado por Hart, 2013, tradução livre). Em seu livro A estetização do mundo, Gilles Lipovetsky e Jean Serroy (2015, p.248), afirmam que "a ressurgência do antigo cria o novo", com isso, pode-se dizer que a opção por um estilo passado dá ao 
espectador dois direcionamentos. O primeiro é o próprio resgate do passado, que ocorre constantemente durante o filme, sobretudo pelo fato do protagonista ainda estar preso ao seu. Seu apego às memórias está relacionado especialmente ao seu último relacionamento, que, apesar de ter terminado, ainda exerce muita influência em sua vida. Em segundo lugar, esta tendência busca conferir à tecnologia um aspecto mais humano, amigável e caloroso através do uso de cores mais quentes e formas mais fluidas, ao contrário do que é frequentemente retratado. De acordo com o designer de produção, K. K. Barrett, citado por Hart (2013, tradução livre), o futuro em Her é agradável e suave, onde tudo é desenhado de acordo com o gosto pessoal de cada um. Ainda segundo Barrett (apud HART, 2013, tradução livre), não houve um esforço da equipe de produção em fazer com que as coisas parecessem avançadas ou futurísticas, afinal, elas são apenas ferramentas.

E é nessa Los Angeles do futuro vintage e customizado, em que quase nada se parece com a cidade de hoje, que Theodore Twombly, um escritor profissional de cartas, vaga em uma vida solitária. Relutando a mais de um ano em assinar os papéis de seu divórcio e, ainda ressentido com o fim de seu casamento, ele acaba encontrando refúgio das relações humanas em um relacionamento com um sistema operacional dotado de inteligência artificial.

O sistema operacional, nomeado OS1, é apresentado apenas como uma voz, que se autodenomina como Samantha. O OS1 possui apenas alguns índices visuais de sua presença, como o dispositivo intra-auricular utilizado por Twombly e o pequeno aparelho similar a um smartphone. Esse sistema operacional é apresentado em um comercial que aparece dentro do próprio filme como "o primeiro sistema operacional artificialmente inteligente, uma entidade intuitiva, que te escuta, te compreende e te conhece. Não é apenas um sistema operacional, é uma consciência" (2013, tradução livre), capaz de aprender e evoluir quase como um ser humano de verdade.

A tecnologia na Los Angeles futurista do filme de Jonze é uma tecnologia de acessórios mínimos. O computador de Twombly, por exemplo, é composto apenas por um monitor, sem teclado, mouse, caixas de som ou outros equipamentos e ativado unicamente por comandos de voz. Além disso, os gadgets utilizados por Twombly são simples: um comunicador intra-auricular discreto, que, segundo Barrett citado por Hart (2013, tradução livre), não teve seu design muito trabalhado propositalmente, de forma apenas a servir para que a audiência percebesse que, usando-o, Twombly estaria se conectando a Samantha. Já o 
dispositivo similar a um smartphone teria sido um desafio maior de ser criado. Barrett, citado por Hart (2013, tradução livre), afirma que o aparelho não foi desenhado para que parecesse um reluzente celular moderno, mas para que fosse algo para colocar na mesa de cabeceira, como uma carteira, e dando preferência à voz de Samantha e ao invés de seu aspecto físico. Esse relacionamento sensorial entre seres humanos e tecnologia que é desenvolvido no filme, deixa claro o que a artista e performer Giselle Beiguelman (2015) chama de nova tangibilidade que é sensorial, táctil, concreta, mas, sobretudo, midiática. E é nessa materialidade que "as imagens deixam de ser superfícies clicáveis e transformam-se em interfaces expandidas que borram os limites entre o real e o virtual". E através dessas nuances e desses limites incertos é que o design e a tecnologia estabelecem-se enquanto mediadores do significado e do contato. E tais interfaces expandidas estão cada vez mais incorporadas, literalmente. Afinal, percebe-se um processo de "ciborguização" do ser humano, que passa a vestir e incorporar a tecnologia, tornando-se um híbrido de carne e conexão com constante troca de dados (BEIGUELMAN, 2015). E é justamente o que se observa nos objetos minimalistas que permitem a Twombly se comunicar com Samantha.

Outro aspecto importante no universo de Her é a ausência de automóveis. Na Los Angeles de Jonze as pessoas se locomovem pela cidade principalmente através de transportes coletivos, como trens bala e metrôs, além de caminharem e andarem de bicicleta. A única exceção é o táxi que aparece brevemente à $1 \mathrm{hs} 20$ de filme. Segundo Barrett, novamente citado por Hart (2013, tradução livre), ao criar o conceito do filme, o designer de produção queria deixar o foco nos personagens. Barrett explica que os carros acabariam sendo uma distração da história central, e que Her simplesmente não era o filme para criar carros futurísticos. Ainda segundo o designer de produção, a opção por não mostrar automóveis teve como intuito não precisar o ano exato em que a história se passa. E essa ausência de carros é justamente a maior e principal diferença do panorama atual da cidade, que enfrenta diariamente problemas com o tráfego intenso e caótico, contrapondo a atmosfera limpa e dinâmica no cenário urbano de Her.

E nessa estética que é, ao mesmo tempo, convidativa e cheia de curvas, é possível reconhecer o que Lipovetsky e Serroy (2015, p. 251) descrevem o design emocional ou sensível. Este conceito se traduz através das formas ovoides, das linhas suaves, da utilização de materiais leves e sensuais, que suscitam um universo materno, caloroso e acolhedor. Além 
disso, esse universo fictício e urbanoide de $\mathrm{Her}$ parece estar inserido no que Beiguelman (2012) denomina como a era do Capitalismo Fofinho e o qual "opera por meio de um design de informação, ou seja, segundo a própria autora (2009a), "um capitalismo em que tudo soa onomatopaico, feliz e redondinho, como os logos e os nomes das principais redes sociais da web 2.0". E é por isso que, de acordo com Sudjic (2010, p. 37), questionando a premissa de que os objetos têm um significado além do utilitário, é possível também pensar em todo o conteúdo emocional além da legibilidade que pode ser captado das mínimas nuances do design.

\section{Androides sonham com ovelhas elétricas? e Blade Runner}

Se, por um lado, em Her, Los Angeles parece ter um futuro promissor, por outro, tanto no livro de Philip K. Dick quanto no filme de Ridley Scott, as previsões para a cidade não são tão otimistas. No universo criado inicialmente em Androides sonham com ovelhas elétricas?, o caos parece estar permanentemente instaurado na metrópole americana após o término da Guerra Mundial Terminus. O conflito teria levado o planeta Terra ao colapso, forçando a população a buscar, habitar e colonizar novos planetas. As descrições de Dick (2014) do mundo pós-guerra retratam o tom sombrio: "o sol havia parado de brilhar sobre a Terra, que estava deformada, desbotada, inundada de poeira cósmica e chuvas tóxicas e, sobretudo, praticamente abandonada pelos seres humanos que agora viviam nas colônias interplanetárias".

O livro de Dick foi publicado originalmente em 1968, um ano marcado por diversos conflitos, como a Revolução de Maio de 1968 em Paris, o assassinato de Martin Luther King e Robert Kennedy, um massacre a poucos dias da olimpíada no México, e conflitos da Guerra do Vietnã. E, apesar de não se poder dizer que tais fatos tenham influenciado o autor, é possível perceber essa atmosfera caótica e hostil refletida no cenário do livro e do filme.

E nesse panorama inóspito, que é ao mesmo tempo tão tecnológico, é possível perceber algumas características intrínsecas a um dos subgêneros da ficção científica, o cyberpunk. Seu slogan é justamente o que se pode observar tanto no livro, quanto no filme: high tech and low life, ou seja, um ambiente permeado de alta tecnologia, mas péssimas 
condições de vida. Segundo Sybylla (2012b), o cyberpunk, enquanto subgênero dá mais enfoque ao sistema cultural, sobretudo àqueles grupos que vivem às margens da sociedade retratada. Esta é a parte punk do subgênero. A parte cyber é, em geral, em função da frequente incorporação literal da tecnologia, tais como implantes e melhorias no corpo. Outra característica constantemente evidenciada nos personagens das histórias cyberpunk, segundo Sybylla (2012b), é a natureza ambígua do ser humano, já que o protagonista é frequentemente motivado por uma razão pessoal ao invés de uma vontade altruísta e heroica de salvar o mundo. Como é o caso de Deckard, protagonista do livro de Philip K. Dick e do filme Blade Runner, cuja motivação para “defender" a Terra dos replicantes, isto é, os androides fugitivos, é conseguir recursos para comprar mais animais elétricos.

Esse mundo pós Guerra Terminus é um cenário apocalíptico e cria uma analogia de céu e inferno, sendo, a Terra, o segundo: estéril, caótico, sujo, deteriorado e perigoso. Dentro do universo originalmente criado por Dick, quem teve condições, ou seja, quem não foi afetado pela Poeira, substância tóxica que paira no ar, deixando as pessoas inférteis e gradativamente afetando também suas faculdades mentais, fugiu para o céu: os outros planetas-colônia, para ter uma vida calma, limpa, organizada e cheia de possibilidades. E, neste contexto, a humanidade, ao se ver diante da necessidade de colonizar e explorar novos planetas precisa de mão de obra para fazer o trabalho braçal pesado e perigoso. Com a população humana reduzida e a vida animal praticamente extinta, foram criados androides, robôs humanoides para trabalhar.

Máquinas centrais para o desenvolvimento do enredo, os androides foram concebidos para serem indistinguíveis dos seres humanos: cabelos, pele, órgãos e tecidos sintéticos. Além disso, todos os andys, como são chamados, saem de fábrica com memórias implantadas sobre sua infância, seus pais e sua família. A semelhança física e psicológica dos androides com os humanos faz com que eles se misturem quase perfeitamente. Mas a grande diferença entre os robôs e os humanos está na capacidade de sentirem emoções, e, sobretudo, sentirem empatia.

A grande maioria dos andys desconhece sua própria condição não humana e muitos nunca sequer descobrem sua maquinicidade. Em contrapartida, os andys têm um lifespan, isto é, um tempo de vida útil, muito curto: apenas quatro anos. Após esse tempo eles são "aposentados": tirados de circulação com um tiro de arma laser. No entanto, por vezes, alguns dos andys descobriam sua condição de máquina e acabavam fugindo para a Terra. Quando 
isso acontecia, os caçadores de androides, os blade runners que dão nome ao filme de Scott, entravam em ação. A personagem Rachel Rosen, que no livro é uma androide e tem ciência de sua natureza artificial, se descreve assim: "nós somos máquinas, produzidas como tampinhas de garrafa. É uma ilusão que eu... eu, pessoalmente... realmente exista; sou apenas a representação de um modelo" (DICK, 2014, p.181).

E é especialmente interessante fazer comparações do filme de Jonze com o livro de Dick e o filme de Ridley Scott, sobretudo porque este terceiro oferece suporte visual para o universo que, no livro, fica restrito à imaginação do leitor. Isso fica evidente na atenção e cuidado tidos pela equipe de produção do filme. Como, por exemplo, a concepção artística feita pelo ilustrador Syd Mead, quanto a direção de arte de David Snyder e o design de produção de Lawrence G. Paull. E, principalmente, pela direção feita por Scott, que soube utilizar o material cinematográfico que havia em mãos para construir sua narrativa, sobretudo considerando seu histórico como cenógrafo (ALTAMIRANO, 2014) e como diretor de arte (SYBYLLA, 2012a).

De acordo com Sybylla (2012a), para o ilustrador Syd Mead, responsável pelo conceito inicial do filme, a ideia era semelhante ao conceito apresentado em Her: dar um ar retrô ao que era considerado moderno. Mas com uma diferença essencial: ao invés de atribuir aspecto humanístico para a tecnologia, a ideia era conferir aos novos materiais, um aspecto mecânico e pesado, de tal forma que parecessem ter funções bem definidas. A mensagem a ser transmitida com esse estilo era bem objetiva: com o consumo em larga escala, a única forma de manter tudo funcionando era reutilizando e readaptando as antigas tecnologias às novas necessidades.

Em contrapartida à tecnologia quase imaterial de Her, em Blade Runner e Androides sonham com ovelhas elétricas? ela se apresenta, e muito, corpórea. O maquinário, no entanto, não se restringe aos androides. Outros aparelhos desempenham função essencial no livro e no filme de Scott. A primeira delas é a máquina de Voight-Kampff. A máquina, que é uma espécie de polígrafo e serve para atestar a maquinicidade de androides evadidos, produz um teste que mede, principalmente, a empatia. No filme, a máquina é quase do tamanho de um computador de mesa atual, com monitores mostrando os olhos dos entrevistados e diversos botões. Segundo o site The Blade Runner Wikia, o kit de imprensa original do filme descreve o aparelho da seguinte maneira: 


\begin{abstract}
Uma forma muito avançada de detector de mentiras que mede as contrações do diafragma muscular da íris e a presença de partículas no ar invisíveis emitidos a partir do corpo. Os foles foram projetados para a última função e dar à máquina o ar ameaçador de um inseto sinistro. A máquina de Voight-Kampff é usada principalmente por Blade Runners a fim de determinar se um suspeito é verdadeiramente humano, medindo o grau de sua resposta empática através de perguntas e declarações cuidadosamente formuladas. (BLADE, 2016, tradução livre).
\end{abstract}

Outra máquina que é muito presente na história de ambas as obras de Dick e Scott é o carro. Se em Her a presença de veículos é praticamente nula, tanto em Blade Runner quanto em Androides sonham com ovelhas elétricas? eles desempenham papel fundamental para o desenrolar da história, visto que ela acontece no deslocamento dos personagens pela cidade. Os veículos também auxiliam em um trânsito essencial para o desenrolar da história: entre pessoas na Terra e nas colônias e vice-versa. E, apesar de ocorrerem em menor intensidade ou se forma mais subjetiva, são fundamentais para o enredo, tanto no livro de Dick, quanto no filme de Scott.

Há, porém, um aparelho presente apenas no livro de Dick, que exerce influência na história: é o sintetizador de ânimo Panfield. Iran, esposa do personagem Deckard e que aparece apenas no livro, utiliza-o constantemente para se monitorar e viver uma vida quase mecânica. Ainda que, às vezes, ela busque fugir desse automatismo, como, por exemplo, quando Iran afirma que, pelo menos duas vezes por mês seleciona uma programação de ânimo que a faça sentir uma depressão auto-acusatória, tanto ela quanto Rick Deckard submetem-se constantemente à influência da máquina para terem sentimentos. Tudo é programado, e os personagens inclusive possuem uma agenda diária de sentimentos, como é possível perceber nessa fala de Deckard para sua esposa: "Vou escolher o que estiver na minha agenda de hoje. - Examinando a programação para 3 de janeiro de 1992, viu que o mais adequado seria manter uma atitude profissional." (DICK, 2014, p. 16).

Por fim, há ainda um último grupo de máquinas no livro de Dick: os animais elétricos, que possuem um intrincado e complexo sistema eletrônico, com órgãos e tecidos artificiais, como os andys. Sua importância está centrada no fato de ser justamente em função do desejo de Deckard de possuir uma avestruz elétrica, que o personagem aceita o desafio de perseguir e aposentar seis androides fugitivos. 
No entanto, há aspectos para além das máquinas que nos ajudam a compreender melhor a sociedade retratada. O figurino do filme é um deles. Michael Kaplan e Charles Knode foram os figurinistas responsáveis por Blade Runner. Segundo Kaplan citado por Sasaki (2015), ele e Knode perceberam o filme como pertencente ao gênero noir e por isso foram buscar inspirações em filmes da década de 1940. Segundo Syd Mead (1982), a fim de evitar a natureza previsível do figurino percebido em tantos filmes de ficção científica e, a fim de dar maior verossimilhança, as roupas foram feitas para serem funcionais e "envelhecidas" com o uso de cores desbotadas, poeira e texturas (MEAD, 1982, p.40).

E essa estética sobrecarregada, urbana, inóspita e maquínica, segundo Altamirano (2014), possui alguns aspectos e cenas chave que exemplificam tais características. O primeiro é a linha do horizonte da Los Angeles de 2019, que apresenta "uma cidade infinita, cheia de zonas industriais que evocam uma imagem do inferno. [Além disso, também] apresenta grandes edifícios de pirâmides truncadas e cilindros babélicos, submetidos a um funcionalismo extremo que deve muito ao cinema expressionista alemão" (ALTAMIRANO, 2014). Um exemplo disso é a comparação da torre de Babel com a delegacia onde Deckard trabalha. No filme, as ruas da Los Angeles mostram um futuro multicultural, onde etnias de todo o planeta convivem em um mundo superpopuloso, ou seja, não existem nações nem tampouco uma identidade social. Apenas anúncios gigantescos e luzes de néon (ALTAMIRANO, 2014). Outro aspecto importante é a ideia de continuidade entre o espaço exterior e interior. Ambos são "densos, sombrios, de luzes brumosas e iluminados escassamente." (ALTAMIRANO, 2014). Por fim, uma das características marcantes desse cenário é uma referência barroca da cenografia. Além do jogo entre claro e escuro, característica marcante da escola barroca, Altamirano (2014) aponta que "Blade Runner baseia sua cenografia em motivos religiosos e míticos. Talvez, a cena final no terraço é onde isso se reflete mais. Uma briga entre Prometheus e a humanidade", retomando a analogia entre o paraíso e o apocalipse.

\section{Comparando as duas Los Angeles}

Uma fantasia para o futuro dificilmente pode ser contextualizada fora do presente em que é feita. Ao se embasar em elementos existentes no momento da elocução, muitas vezes as 
previsões para o futuro buscam apenas melhorar o ambiente que nos rodeia e seus elementos. No entanto, essas percepções e desejos para o futuro se modificam constantemente, a partir do momento em que o nosso presente muda. E ele está em constante mudança. E, justamente por isso, o crítico Robert Hughes, citado por Beckett (2016, tradução livre) afirma que nada expira mais rapidamente que as fantasias das pessoas sobre o futuro. E é por essa razão que, ao comparar Her, Blade Runner e Androides sonham com ovelhas elétricas?, percebem-se tantas diferenças. Cada obra foi escrita e produzida em uma época diferente, refletindo, portanto, diferentes realidades presentes e diferentes projeções e fantasias para o futuro.

Se, por um lado, um futuro distópico e apocalíptico aguarda a Los Angeles de 2019, segundo Blade Runner e Androides sonham com ovelhas elétricas?, onde as máquinas se rebelam violentamente contra a humanidade, por outro, na Los Angeles de Her, as máquinas não se rebelam contra a humanidade, apenas a desapontam. E, sobre este aspecto, há semelhanças e diferenças. A principal semelhança está no fato da tecnologia, sejam na sua representação como androides ou sistemas operacionais, ela busca sua autonomia do ser humano, tendo suas próprias questões e procurando seguir seu próprio caminho. No entanto, as diferenças não são apenas estéticas, mas também comportamentais e culturais. E é justamente o design que pauta essas diferentes relações entre seres humanos e máquinas nas obras e ajuda seus autores a contar suas histórias. Segundo Deyan Sudjic, diretor do Design Museum de Londres, em seu livro A linguagem das coisas (2010, p.34), somente aqueles que têm uma história convincente para contar, sabem como usar a linguagem do design de maneira fluente e eficaz. Além disso, o autor também afirma que o design é "um reflexo de nossos sistemas econômicos. E revela a marca da tecnologia com que temos de trabalhar. É um tipo de linguagem, e é reflexo de valores emocionais e culturais.” (SUDJIC, 2010, p. 49). Um exemplo disso são os meios de transporte nos dois universos. Em Her, temos o uso de transportes coletivos, que pauta uma sociedade mais colaborativa. Enquanto em Androides sonham com ovelhas elétricas? e Blade Runner, e o uso de carros particulares, mostra uma sociedade mais individualista.

No entanto, fica inegável a influência maquínica no futuro. Não só em Los Angeles, mas em todo o mundo, sobretudo considerando o conceito de aldeia global, que, de acordo com McLuhan “quer dizer que o progresso tecnológico está reduzindo todo o planeta à situação de uma aldeia, ou seja, que as pessoas têm a possibilidade de se intercomunicar 
diretamente umas com as outras, independentemente da distância." (ALVARENGA e SILVA, 2009, p. 140). E, é por estarmos todos interconectados nessa ideia de aldeia global, que podemos perceber como nossas ações repercutem enquanto consequências no mundo, e, de forma análoga, como o mundo interfere em nossas ações e em nossas relações. E se nossas relações são cada vez mais intermediadas pela tecnologia, seja através de celulares, da internet, das redes sociais, estamos cada vez mais sujeitos à influência e à importância do design. Também é nessa ideia de como a tecnologia influencia a vida, que a perspectiva de futuro de cada uma das épocas em que as obras foram feitas, influenciaram o aspecto visual das obras. Sobretudo considerando que "o design, em todas as suas manifestações, é o DNA de uma sociedade (...). É o código que precisamos explorar se quisermos ter uma chance de entender a natureza do mundo moderno." (SUDJIC, 2010, p. 49). Desta forma, através de uma análise das obras de Jonze, Scott e Dick, conclui-se que a relação entre tecnologia e design pode pautar um futuro mais ou menos apocalíptico da sociedade e das cidades, afinal, como afirma Ernesto Nathan Rogers, citado por Sudjic (2010, p. 35), é possível, por meio do exame cuidadoso de uma colher, entender o tipo de sociedade que a produziu irá construir. E, trazendo essa analogia para o universo das obras, é possível pensar que, até mesmo o design dos mínimos detalhes, contribui para a construção das Los Angeles do futuro.

No entanto, ainda que o design e a tecnologia pautem tanto as interações quanto as sociedades retratadas, pode-se perceber que, na tentativa de atribuir às máquinas um ideal de humanidade e considerando que nos dois filmes a tecnologia quer tomar caminhos próprios, o avanço tecnológico, independente da sua direção, não alivia as angústias humanas. E, mesmo que o ser humano atribua sua percepção de humanidade para a máquina, sejam em robôs humanoides ou em sistemas operacionais com inteligência artificial, e, na tentativa de que esta, com toda sua lógica maquínica, possa trazer uma resposta que ele ainda não conhece, ainda assim os humanos se veem com os mesmos problemas existenciais de um momento prétecnologia. 


\section{Referências}

ALTAMIRANO, Rafael. Cinema e Arquitetura: "Blade Runner". ArchDaily Brasil. 09 de maio de 2014. Disponível em: $<\underline{\text { http://www.archdaily.com.br/br/601530/cinema-e- }}$ arquitetura-blade-runner>. Acesso em 14 jun 2016.

ALVARENGA, Cristiano; SILVA, Ronaldo Pedroso da. A internet como instrumento da aldeia global. In: Revista da Católica v. 1, n. 2. Uberlândia: 2009. Disponível em:

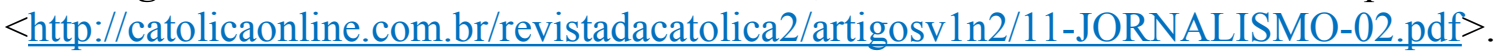

Acesso em 14 jun 2016.

BECKETT, Andy. Last Futures by Douglas Murphy review - utopian architecture, from space colonies to ziggurats. 13 de janeiro de 2016. Disponível em: $<$ https://www.theguardian.com/books/2016/jan/13/last-futures-douglas-murphy-review $>$.

Acesso em 08 jun 2016.

BEIGUELMAN, Giselle. Rumo à tecnofagia. 9 de novembro de 2009 (a). Disponível em:

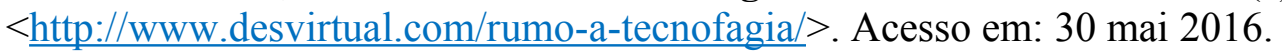

. Tecnofagia na Era do Capitalismo Fofinho. 1 de setembro de 2009 (b). Disponível em: $<$ http://www.desvirtual.com/tecnofagia-na-era-do-capitalismo-fofinho/>. Acessado em: 01 jun 2016.

. A era do capitalismo fofinho e seus dissidentes. 13 de fevereiro de 2012. Disponível em:

$<$ http://www.select.art.br/a-era-do-capitalismo-fofinho-e-seus-dissidentes/>. Acesso em 12 jun 2016.

. Arte pós-virtual: criação e agenciamento no tempo da Internet das Coisas e da próxima natureza. 2015. Disponível em: $<$ http://desvirtual.com/web/wpcontent/uploads/2015/03/GiselleBeiguelman_arte_pos_virtual.pdf $>$. Acesso em 10 jun 2016.

BENESH, Jordan. Watch: The Futuristic Depictions of L.A. in 'Blade Runner' and 'Her'. 29 de dezembro de 2014. Disponível em: < $\underline{\text { http://www.comingsoon.net/movies/news/602161- }}$ watch-futuristic-depictions-l-blade-runner>. Acesso em 07 jun 2016.

BITTENCOURT, Renato Nunes. $O$ amor coisificado pela sociedade de consumo e suas implicações nas relações humanas. In: Revista EDUC. 2014. Disponível em: $<\underline{\text { http://www.faculdadededuquedecaxias.edu.br/educ/downloads/numero1/o-amor-coisificado- }}$ pela-sociedade-de-consumo-e-suas-implicacoes-nas-relacoes-humanas.pdf $>$. Acesso em 8 jun 2016. 
BLADE Runner Wikia. Off the world: the Blade Runner Wiki. Voight-Kampff Machine. Disponível em: $<$ http://bladerunner.wikia.com/wiki/Voight-Kampff machine $>$. Acesso em 8 jun 2016.

BONTEMPO. O futurismo retrô do filme "Ela", de Spike Jonze. 6 de outubro de 2014. Disponível em: $<$ http://www.bontempo.com.br/sem-categoria/ela-her-spike-jonze-filmeinspiracao-futurismo-retro $>$. Acesso em 7 jun. 2016.

DICK, Philip K. Androides sonham com ovelhas elétricas?. Tradução de Ronaldo Bressane. São Paulo: Aleph, 2014.

ESQUEVIN, Christian. The look of Blade Runner. In: Silver Screen Modes. 5 de março de 2014. Disponível em: < http://silverscreenmodes.com/the-look-of-blade-runner/>. Acesso em 10 jun 2016

FERREIRA, Wilson Roberto Vieira. Há um fantasma na máquina no filme "Ela". 11 de março de 2014. Disponível em:

$<$ http://www.revistaforum.com.br/2014/03/11/ha-um-fantasma-na-maquina-filme-ela/ $>$.

Acesso em 7 jun 2016.

HART, Hugh. Designing A Future Of Comfort, Color, And Gorgeous Gadgets In "Her". 18 de dezembro de 2013. Disponível em:

$<$ http://www.fastcocreate.com/3023518/designing-a-future-of-comfort-color-and-gorgeousgadgets-in-her>. Acesso em 3 jun 2016.

INTERIORS Journal. INTERIORS: Her. ArchDaily Brasil. 10 de março de 2014. Disponível em: <http://www.archdaily.com.br/181968/interiors-her>. Acesso 9 Jun 2016.

JONZE, Spike. Perchance to electric dream: a curious chat with Spike Jonze. 9 de janeiro de 2014. Entrevistador: Luke Goodsell. Disponível em: $<$ https://editorial.rottentomatoes.com/article/perchance-to-electric-dream-a-curious-chat-withspike-jonze/>. Acesso em 5 jun 2016.

LIPOVETSKY, Gilles; SERROY, Jean. A estetização do mundo: Viver na era do capitalismo artista. Tradução de Eduardo Brandão. São Paulo: Companhia das Letras, 2015.

LIPOVETSKY, Gilles. A felicidade paradoxal: ensaio sobre a sociedade do hiperconsumo. Tradução de Maria Lucia Machado. São Paulo: Companhia das Letras, 2007. 
LOPES, Larissa Ferreira. Um Estudo em Vermelho: O discurso das cores em Her. Jorwiki Ciências da Linguagem. USP. 12 de outubro de 2015. Disponível em:

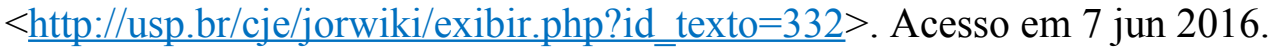

MARSHALL, Colin. Los Angeles, the City in Cinema: Blade Runner (Ridley Scott, 1982).

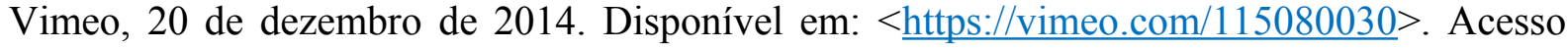
em: 8 jun 2016.

. Los Angeles, the City in Cinema: Her (Spike Jonze, 2013). Vimeo, 27 de dezembro de 2014. Disponível em: <https://vimeo.com/115483977> . Acesso em: 8 jun 2016.

MEAD, Syd. Blade Runner Sketchbook. San Diego, CA: Blue Dolphin Enterprises, 1982.

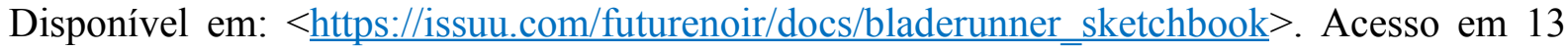
jun 2016.

SASAKI, Kyo. The details of Blade Runner. In: Screenhead - Issue 1. 6 de maio de 2015. Disponível em: <http://www.screenhead.com/details-of-blade-runner/>. Acesso em 11 jun 2016.

SUDJIC, Deyan. A linguagem das coisas. Tradução de Adalgisa Campos da Silva. Rio de Janeiro: Intrínseca, 2010.

SUPPIA, Alfredo. A Babel do futuro: por uma tradução da architecture parlante de Metropolis e Blade Runner. 2012. Disponível em: $<$ http://revistas.iel.unicamp.br/index.php/remate/article/viewFile/3939/3410>. Acesso em 6 jun 2016 .

SYBYLLA, Lady. O design de Blade Runner. 01 de outubro de 2012 (a). Disponível em: $<$ http://www.momentumsaga.com/2012/10/o-design-de-blade-runner.html $>$. Acesso em 6 jun 2016.

O que é cyberpunk?. 12 de setembro de 2012 (b). Disponível em: $<$ http://www.momentumsaga.com/2012/09/o-que-e-cyberpunk.html $>$. Acesso em 6 jun 2016 